\title{
Interest of using a model combining carbonation/chloride ingress and depassivation to better anticipate the rehabilitation of concrete structures
}

\author{
Lucie Schmitt ${ }^{1,2, *}$, Jonathan Mai-Nhu ${ }^{1}$, Frédéric Duprat ${ }^{2}$, Thomas De Larrard ${ }^{2}$, and Patrick Rougeau ${ }^{1}$ \\ ${ }^{1}$ CERIB, Centre d'Etudes et de Recherches de l'Industrie du Béton, FRANCE \\ ${ }^{2}$ Université de Toulouse, UPS, INSA, LMDC (Laboratoire Matériaux et Durabilité des Constructions), 135 Avenue de Rangueil, F- \\ 31 077, FRANCE
}

\begin{abstract}
Mastering and optimizing the durability of concrete structures and also the rehabilitation of concrete structures is a major challenge for all actors of the concrete construction field. An experimental program is conducted to get a complete characterization of the mechanical, chemical and physical properties of four concretes and their performances towards the main aggressive environment for the reinforcement corrosion. The evaluated durability properties are chloride migration, porosity, water absorption and carbonation. Moreover, for each concrete, some reinforced specimens are manufactured to measure the electrochemical properties of the reinforcement such as potential. The project achievements are used to optimize and improve the durability model SDReaM-crete developed by Cerib and LMDC. This model can simulate the migration of chlorides, the combination of this migration with the mechanism of carbonation and the corrosion of reinforcing bars according to wetting-drying cycles. Finally, the present work aims to optimize the sizing of the cover thickness for new structures and to facilitate the lifespan prediction for existing structures. This paper describes the model SDReaM-crete and its recent improvements. Some experimental results and some interpretations as well as simulations made with SDReaMcrete are also presented.
\end{abstract}

\section{Introduction}

The corrosion of steel reinforcement, primarily due to carbonation and/or salt exposure, is a major cause of the deterioration of the reinforced concrete structures. Mastering and optimising the durability of prefabricated products or concrete structures, whether they are structural, architectural or intended for sewerage, is a major challenge for the entire profession. A lot of researches have been devoted to the analysis and the modelling of the carbonation or chloride ingress in the concrete [1-8]. In his work, Mai-Nhu [7] proposed an original model called SDReaM-crete which takes into account the coupling between carbon dioxide effect and chloride ingress as well as oxygen and moisture transfers. This model also computes the depassivation phase due to the chloride ions or the concrete carbonation in a probabilistic context and the growth of the corrosion products. Less attention has been paid however on the need to simulate two different layers of corrosion products rather than one. Many authors studied the corrosion products and showed that they are divided in two parts $[9,10]$. These two layers have an influence on the corrosion rate as their properties in particular the porosity have an influence on the oxygen access to the reinforcement. This work consists in developing the propagation of the corrosion in SDReaM-crete and also validates this model from the penetration of the aggressive species into blended cement matrix point of view.

In order to refine and validate the model an experimental campaign was conducted and has led to a characterization of the chemical and physical properties of four concretes including their performances towards the main aggressive environment on the reinforcement corrosion.

This model was developed and is improved in order to help the actors of the concrete profession in the prediction of the existing structures lifespan or in the definition of the cover thickness and material characteristics for new constructions.

\section{Model presentation}

\subsection{Carbonation}

Before presenting the model it is necessary to remind the fundamental physics and chemistry of the carbonation phenomenon. In a non-carbonated concrete, steel

* Corresponding author: 1. schmitt@,cerib.com 
reinforcements are generally covered by a passive layer of iron oxide mainly due to the high alkalinity of the interstitial solution. This film acts as a protective layer to prevent the embedded steel from corrosion. The main effect of carbonation phenomenon is to decrease the $\mathrm{pH}$ of the concrete pore solution from 13.5 to levels below 9 . At low $\mathrm{pH}$, the protective layer loses its stability and the corrosion of steel reinforcement can start in presence of moisture and oxygen.

The reactions of carbonation phenomenon are summarized hereafter.

Dissolution of carbon dioxide in the concrete pore solution:

$$
\begin{aligned}
& \mathrm{H}_{2} \mathrm{O}+\mathrm{CO}_{2}{ }_{(g)} \rightarrow \mathrm{HCO}_{3-}^{-}(a q)+H^{+}{ }_{(a q)} \\
& \mathrm{HCO}_{3}^{-}(a q) \rightarrow \mathrm{CO}^{2^{2-}}(a q)+\mathrm{H}^{+}{ }_{(a q)}
\end{aligned}
$$

Dissolution of calcium hydroxide contained in the hardened cement paste:

$$
\mathrm{Ca}(\mathrm{OH})_{2(s)} \rightarrow \mathrm{Ca}^{2+}{ }_{(a q)}+2 \mathrm{OH}^{-}(a q)
$$

Reaction between dissolved carbon dioxide and dissolved calcium hydroxide:

$$
\begin{aligned}
& \mathrm{Ca}^{2+}{ }_{(a q)}+2 \mathrm{OH}_{(a q)}^{-}+2 \mathrm{H}_{(a q)}^{+}+\mathrm{CO}_{3}{ }_{(a q)}^{2-} \rightarrow \underset{\mathrm{CaCO}_{3}(s)}{+2 \mathrm{H}_{2} \mathrm{O}}
\end{aligned}
$$

It is to be noted that reaction (4) exists also for other hydrates. Hyvert et al showed that aluminate phases and C-S-H carbonate less rapidly than Portlandite, nevertheless these hydrates cannot be neglected, particularly at high partial pressure of $\mathrm{CO}_{2}$ [3]. It is wellknown that the saturation degree of the concrete and the moisture flows play an important role in the carbonation mechanism. Carbonation preferably occurs when relative humidity is within the range $55 \%$ to $80 \%$ and the transport of carbon dioxide is a function of moisture content. Therefore it is necessary to take into account the moisture flow through wetting-drying cycles when modelling the carbonation of concrete.

Carbon dioxide is one of the constituents of the gaseous phase. We consider both the $\mathrm{CO}_{2}(\mathrm{~g})$ transport and the carbonate ions convection in water. Carbon dioxide is soluble in water and reacts in pore solution to form carbonic acid, bicarbonate ions and then carbonate ions $\mathrm{CO}_{3}{ }^{2-}$ :

$$
\left[\mathrm{CO}_{3}{ }^{2-}\right]=Q_{1}\left(\mathrm{P}_{\mathrm{CO} 2} / \mathrm{RT}\right)
$$

where $\mathrm{Q}_{1}$ is a function which depends on the $\mathrm{pH}$, the hydration equilibrium constants of carbonic acid, bicarbonate and carbonate ions, $\mathrm{P}_{\mathrm{CO} 2}$ is the partial pressure of $\mathrm{CO}_{2}(\mathrm{~Pa}), \mathrm{R}$ is the gas constant $(\mathrm{J} / \mathrm{mol} / \mathrm{K})$ and $\mathrm{T}$ is the temperature $(\mathrm{K})$.

The transport of carbonate ions is considered by its mass balance equation: $\varphi \operatorname{Sr}\left(\partial\left[\mathrm{CO}_{3}{ }^{2-}\right] / \partial t\right)=-\operatorname{div}\left(\boldsymbol{\Phi}_{\mathrm{CO}^{2-}}\right)-\beta_{\mathrm{CaCO} 3}+\beta_{\mathrm{CO}^{2-}}$

where $\beta \mathrm{x}$ are factors that take into account the reaction between the calcium part of each hydrates and carbonate ions, $\varphi$ is the porosity and $\mathrm{Sr}$ is the saturation degree. The particularity of this model lies in the

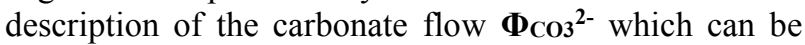
described as the addition of a diffusive part and a convective part with the water movement.

$\boldsymbol{\Phi}_{\mathrm{CO}^{2-}}{ }^{2-}=-D_{\mathrm{CO}_{3}{ }^{2-}(\mathrm{Sr}=1)} R_{d l} \operatorname{grad}\left[\mathrm{Co}^{2-}\right]+\boldsymbol{\Phi}_{\text {water }}\left[\mathrm{CO}_{3}{ }^{2-}\right]$

where $\mathrm{D}_{\mathrm{CO}^{3}}{ }^{2-}(\mathrm{Sr}=1)$ is the diffusion coefficient of carbonates in the liquid phase, $\mathrm{R}_{\mathrm{dl}}$ is the resistance of the porous media to the $\mathrm{CO}_{3}{ }^{2-}$ diffusion which depends on the saturation degree, $\boldsymbol{\Phi}_{\text {water }}$ is the water velocity.

Hyvert [3] highlighted the dependency of the carbonation kinetics on the $\mathrm{CO}_{2}$ pressure versus the hydrate type. In the present model this dependency is considered via the difference between the C-S-H and other hydrates carbonation rates. This difference is taken into account by the constant $\mathrm{n}$ (equation 8 ). The kinetic of the formation of the calcium carbonate can be expressed as a function of the concentration of carbonates.

$\beta_{\mathrm{CaCO} 3}=\left(1 / \tau_{2}\right)\left[\mathrm{CO}_{3}{ }^{2-}\right]\left(\left[\mathrm{Ca}_{\mathrm{CH}}\right]+\left[\mathrm{Ca}_{\mathrm{Afm}}\right]+\left[\mathrm{Ca}_{\mathrm{FS}}\right]\right)+$ $\left(1 / \tau_{2}\right)\left[\mathrm{CO}_{3}^{2-}\right]^{n}\left[\mathrm{Ca}_{\mathrm{C}-\mathrm{S}-\mathrm{H}}\right]$

In the equation 8 we can see that the carbonation of the Friedel salts is accounted for. This coupling between carbonation and chloride ingress is the first important originality of SDReaM-crete.

This model also takes into account a variation of porosity due to the carbonation of the hydrates and can calculate the $\mathrm{pH}$ of the interstitial solution due to the carbonation of portlandite.

\subsection{Chloride ingress}

As mentioned earlier (section 1) in a healthy concrete the rebars are protected by a protective layer called passive layer made of metallic oxides and hydroxides. When the chloride concentration in concrete reaches a threshold level, this protective oxide layer of steel bar is broken down, and the corrosion process can start under favorable moisture and oxygen accessibility conditions. In the literature the threshold level necessary to break the passive layer varies between $0.1 \% / \mathrm{bw}$ (binder weight) and $8.34 \% / \mathrm{bw}$ and it is often called Ccrit. Angst et al. [11] made a synthesis of these different Ccrit.

Therefore, chloride penetration into concrete is a critical issue in the process of corrosion of reinforcing steel bars. In cyclic wetting/drying conditions, chloride ions penetrate into concrete by convection with the liquid phase and then by diffusion process in the pore solution when the liquid phase is continuous. Cyclic wetting/drying conditions allow for deeper penetration of aggressive ions. Once again, the saturation degree of the concrete and the moisture flows play an important role in this mechanism. 
The chloride diffusion in the aqueous phase can be described by the following mass balance equation: $\varphi \operatorname{Sr}\left(\partial\left[\mathrm{Cl}^{-}\right] / \partial t\right)=\boldsymbol{- \boldsymbol { d i v }}\left(\boldsymbol{\Phi}_{C l-}\right)-\beta_{C-S-H}-\beta_{F S}+\beta_{F S} \mathrm{Carbo}$

where $\beta \mathrm{x}$ are factors that take into account both the physical fixation of chlorides in the C-S-H and the chemical fixation of chlorides to AFm hydrates to form Friedel salts. $\beta_{\mathrm{FS}}{ }^{\mathrm{Carbo}}$ is a source term taking into account carbonation of the Friedel salts, which can cause a release of chloride ions in the pore solution. The carbonation state of $\mathrm{C}-\mathrm{S}-\mathrm{H}$ and AFm hydrates is also considered: the chloride binding capacity is strongly reduced when carbonation occurred [12]. The chloride flow can be described like the carbonate flow.

$$
\boldsymbol{\Phi}_{C l-}=-D_{C l-} \operatorname{grad}\left[\mathrm{Cl}^{-}\right]+\boldsymbol{\Phi}_{\text {water }}\left[\mathrm{Cl}^{-}\right]
$$

Where $\mathrm{D}_{\mathrm{Cl}}^{-}$is varying within the saturation of concrete in the same way as the diffusion coefficient of carbonates ions.

\subsection{Moisture transfer}

It has been shown that the saturation degree of the concrete and the moisture flow play an important role in the carbonation mechanism and the chloride diffusion [13]. The water movements are described by using the mass balance equation of water proposed by Ranaivomanana [14].

$\left[\rho_{l} \varphi\left(\partial S_{r} / \partial h\right)+p_{v s a t}\left(M_{H 2 O} / R T\right) \varphi\left(1-S_{r}-h\left(\partial S_{r} / \partial h\right)\right]\right.$ $(\partial h / \partial t)=\operatorname{div}\left(\rho_{l}^{2}\left(k_{l} / \eta_{l}\right) k_{r l} p_{v s a t}\left(R T / M_{H 2 O}\right)(1 / h)\right.$ gradh + $\left(M_{H 2 O} / R T\right) R_{d} D$ gradh $)+\beta_{H 2 O}$

Where $\beta_{\mathrm{H} 2 \mathrm{O}}$ is an additional source term of water corresponding to the dehydration of portlandite during the carbonation.

\subsection{Depassivation and corrosion}

The corrosion modeling part is dealing with the equation proposed by Huet et al. and Chitty et al. $[15,16]$.

$$
\boldsymbol{V}_{\text {corr }}=H(4 / 3)\left(M_{F e} / \rho_{F e}\right)\left(1 / \tau_{5}\right) \varphi S_{r} \boldsymbol{\Phi}_{\boldsymbol{O} 2}
$$

where $\tau_{5}$ is a kinetic constant (s) and $\mathrm{H}$ is an additional function which takes into account the depassivation conditions due to either the carbonation (decrease of $\mathrm{pH}$ from 13.5 to 9) or the chlorides (increase of the free chlorides from $45 \mathrm{~mol} / \mathrm{m}^{3}$ to 440 $\mathrm{mol} / \mathrm{m}^{3}$ according to Angst [11]) is considered. It is important to note that the depassivation part is probabilistic in SDReaM-crete.

\section{Improvement of the model}

In SDReaM-crete corrosion part is simulated with the equation 12 . This equation considers only the creation of one layer of corrosion products and takes into account the porosity of the concrete. In their works Chitty and L'Hostis showed that the corrosion products are divided in two parts which have different diffusion properties [9, 10]. The first layer is called dense product layer or stable layer and it is adjacent to the rebar. This layer has a weak porosity and is made with stables oxides. The second layer is called unstable layer and is localised between the stable layer and the cement matrix. This layer is porous and not stable. When the corrosion begins the unstable layer is growing. Then the oxides of this layer react to form the stable one. Few oxides of the unstable layer can migrate to the cement matrix.

Nguyen et al. [17] proposed a model which considers these two different layers and their different properties.

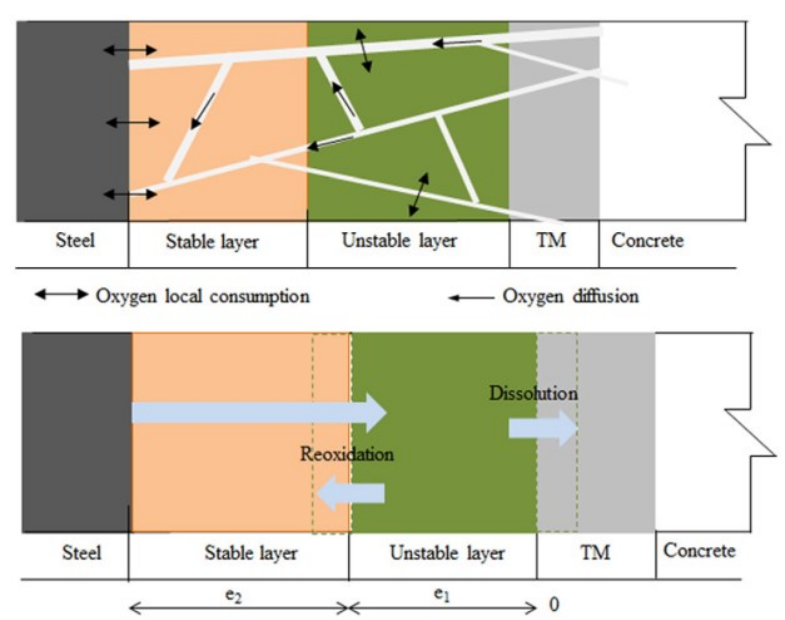

Fig. 1. Schema of the two layers of corrosion products

The unstable layer (UL) is reactive so it consumes oxygen. The consummation of oxygen depends on the porosity $\left(\varphi_{U L}\right)$, on the specific surface of the porosity $\left(\mathrm{S}_{\mathrm{UL}}\right)$ and on a kinetic term $\left(\mathrm{k}_{\mathrm{UL}}\right)$ (equation 13).

$\left(d\left[\mathrm{O}_{2}\right] / d t\right)=D_{U L} \operatorname{div}\left(\operatorname{grad}\left[\mathrm{O}_{2}\right]_{l}\right)-k_{U L} s_{U L} \varphi_{U L}\left[\mathrm{O}_{2}\right]_{l}$

The stable layer (SL) is not reactive toward oxygen. The transport in it is diffusive (equation 14).

$\left(d\left[\mathrm{O}_{2}\right] / d t\right)=D_{S L} \operatorname{div}\left(\operatorname{grad}\left[\mathrm{O}_{2}\right]_{l}\right)$

Where $\mathrm{D}_{\mathrm{UL}}$ and $\mathrm{D}_{\mathrm{SL}}$ are the diffusion coefficient of the oxygen into the unstable layer and the stable layer respectively.

In a steady state regime the previous equations can be rewritten (the thickness of the concrete is really high compared to the thickness of the corrosion products).

$0=D_{U L} \operatorname{div}\left(\operatorname{grad}\left[\boldsymbol{O}_{2}\right]_{l}\right)-k_{U L} s_{U L} \varphi_{U L}\left[\mathrm{O}_{2}\right]_{l}$

$0=D_{S L} \operatorname{div}\left(\operatorname{grad}\left[\mathrm{O}_{2}\right]_{l}\right)$

To solve these two equations two assumptions are made:

- Oxygen cannot penetrate into steel so oxygen flows at $\mathrm{x}=\mathrm{e}_{2}$ is equal to 0 . 
- There is continuity between the two oxide layers.

So the solution for the unstable oxide layer $(x=[0$, $\left.\mathrm{e}_{1}\right]$ ) is given by equation 17 .

$$
\left[\mathrm{O}_{2}\right]_{U L}=\left[\mathrm{O}_{2}\right]_{\text {out }} \cosh \left(x / \lambda_{U L}\right)+\gamma \lambda_{U L}\left[\mathrm{O}_{2}\right]_{\text {out }} \sinh \left(x / \lambda_{U L}\right)
$$

And the solution for the stable oxide layer $\left(\mathrm{x}=\left[\mathrm{e}_{1}\right.\right.$, $\left.\mathrm{e}_{1}+\mathrm{e}_{2}\right]$ ) is given by equation 18 .

$$
\begin{aligned}
& {[O 2]_{S L}=[O 2]_{\text {out }}\left[\left(e_{2} / \lambda_{U L}\right) \sinh \left(e_{1} / \lambda_{U L}\right)+e_{2} \gamma \cosh \left(e_{1} / \lambda_{U L}\right)\right.} \\
& \left.+\cosh \left(e_{1} / \lambda_{U L}\right)+\gamma \lambda_{U L} \sinh \left(e_{1} / \lambda_{U L}\right)\right]
\end{aligned}
$$

With $\lambda_{\mathrm{UL}}$ a constant which depends on $\mathrm{D}_{\mathrm{UL}}, \mathrm{k}_{\mathrm{UL}}$ and SUL and $\gamma$ function of $\lambda_{\mathrm{UL}}, \mathrm{e}_{1}, \mathrm{e}_{2}$ and $\mathrm{D}_{\mathrm{SL}}$.

At the rebar interface $\left(x=e_{2}\right)$, the oxygen flow is linear with the oxygen concentration (equation 19).

$$
W_{O 2, S L}=k_{S L} S_{r} \varphi_{S L}\left(R T / K_{H}\right)\left[O_{2}\right]_{S L}
$$

With $\mathrm{k}_{\mathrm{SL}}$ a kinetic constant and $\mathrm{K}_{\mathrm{H}}$ the henry constant.

A consumption of oxygen takes place in the unstable oxide layer $\left(\mathrm{x}=\left[0, \mathrm{e}_{1}\right]\right)$ so the quantity of reduced oxygen in the unstable layer can be calculated in integrating the source term of equation 15 .

$$
W_{O 2, U L}=k_{U L} S_{r} \varphi_{U L}\left(R T / K_{H}\right) \int_{0}^{e}{ }^{e}\left[O_{2}\right]_{U L}(x) d x
$$

Then the growth of the corrosion products can be calculated with equation based on the one proposed by Huet and Chitty (equation 12).

The formation of the stable oxide layer depends on the transformation of the unstable products on stable products and on the quantity of oxygen in the unstable layer. So for a time step the quantity of stable oxide created is given by equation 21 .

$\Delta e_{S L}=(4 / 3)\left(M_{F e} / \rho_{F e}\right) W_{O 2, S L} \Delta t$

For the growth of the unstable oxide layer, there is a competition between an inlet of oxygen coming from the outside (within the concrete) and an outlet of oxygen toward the stable layer. Also, there is a part of unstable oxide which migrates to the cement matrix. This phenomenon is represented by the coefficient $\alpha_{\mathrm{TM}}$ in the equation 22 .

$\Delta e_{U L}=(4 / 3)\left(M_{F e} / \rho_{F e}\right)\left[W_{O 2, U L}\left(1-\alpha_{M T}\right)-W_{O 2, S L}\right] \Delta t$

Finally, for one step time the total corrosion product formed is given by the sum of equation 21 and 22 .

\section{Experimental results and application of the model}

In this section some experimental results are presented. The aim of these performed tests is twofold:
- To obtain some input data for the simulations (porosity and chloride ions migration).

- To optimize the model for different concrete mixes (carbonation and sorption/desorption).

Then some numerical results coming from SDReaM-crete are presented.

\begin{tabular}{|c|c|c|c|c|c|}
\hline Constituents & Units & F1 & F2 & F4 & F5 \\
\hline CEM I $52.5 \mathrm{~N}$ & \multirow{5}{*}{$\mathrm{kg} / \mathrm{m}^{3}$} & 324 & 242 & 404 & 309 \\
\hline Limestone filler & & 39 & 10 & 64 & 10 \\
\hline Blast furnace slag & & 0 & 124 & 0 & 129 \\
\hline $0 / 4$ & & 942 & 931 & 937 & 923 \\
\hline $4 / 8$ & & 770 & 762 & 767 & 755 \\
\hline Efficient water & $1 / \mathrm{m}^{3}$ & 198 & 200 & 162 & 168 \\
\hline Total binder & $\mathrm{kg} / \mathrm{m}^{3}$ & 363 & 376 & 468 & 448 \\
\hline $\mathrm{W}_{\mathrm{eff}} / \mathrm{B}_{\mathrm{tot}}$ & - & 0.55 & 0.53 & 0.35 & 0.38 \\
\hline
\end{tabular}

\subsection{Concrete formulation}

In this study four concretes were studied. Their compositions are presented in the table 1 .

Table 1. Concretes compositions

All specimens are demoulded after 24 hours. They were wrapped into aluminium and placed in a laboratory $\left(20^{\circ} \mathrm{C}, 50 \% \mathrm{RH}\right)$ for 48 hours. Then they were unwrapped and leave in the same laboratory until the test beginning (90 days).

\subsection{Tests and results}

\subsubsection{Porosity}

Porosity to water was measured by total saturated water method according to NF P 18-459 standard [18]. The samples have been weighted both below water and in air before being oven dried at a temperature of $105^{\circ} \mathrm{C}$ until constant mass. The average of three measurements was used to evaluate the water porosity. Figure 2 presents the results of the porosity test.

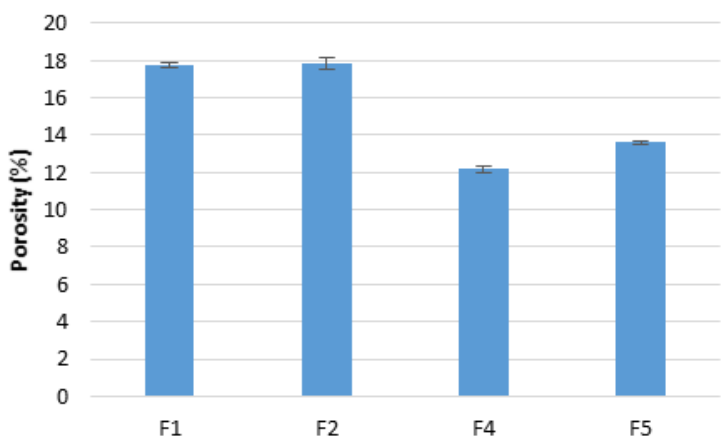

Fig. 2. Result of porosity test

The porosity of concrete controls the main transfer phenomena (water, carbon dioxide, chloride ions, oxygen). Moreover it is a durability indicator and an input data for the model SDReaM-crete.

As it is expected the compact concretes (F4 and F5) present a lower porosity that F1 and F2. 


\subsubsection{Sorption/desorption}

Sorption/desorption was performed according to the standard NF EN ISO 12571 [20]. The result is the mean value of three samples. The samples were weighed each day and we considered that the mass is constant when the variation of the mass between two consecutives measures is less than $0.05 \%$.

Sorption/desorption properties have to be characterize because all the transfer properties are governed by the moisture of the concrete. However, this test can take several weeks to be completed. Based on the results obtained in this study a method has been developed to optimize the calculation of the desorption properties in the model SDReaM-crete.

An isotherm is chosen among the tested concrete to be the reference. The desorption isotherm of the concrete F2 is chosen as the reference isotherm. Then we apply a homothety $\mathrm{g}(\mathrm{h}, \beta)$ to the reference isotherm:

$S_{r}(h)=S_{r(r e f)}(h) g(h, \beta)$

With $g(h, \beta)$ the homothety which is equal to equation 24 .

$$
g(h, \beta)=h+(1-h)\left[\left(S_{r(r e f)}(0.5)+\Delta S_{r} \beta\right) / S_{r(r e f)}(0.5)\right]
$$

where $\Delta \mathrm{Sr}$ is the variation of the isotherm around the reference isotherm (equal to 0.17), $\mathrm{S}_{\mathrm{r}(\text { ref }}$ the saturation rate of $\mathrm{S}_{\mathrm{r}(\mathrm{ref})}(\mathrm{h})$ at $\mathrm{h}=0.5$ and $\beta$ is the direction of the variation of the isotherm $(\beta=[-1,1])$. It is important to note that this way to calculate $\mathrm{S}_{\mathrm{r}}(\mathrm{h})$ is valid for a relative humidity between 0.5 and 1 .

Figure 3 presents the sorption properties of the four concretes as well as the isotherms $\mathrm{S}_{\mathrm{r}}$ with three different values of $\beta$.

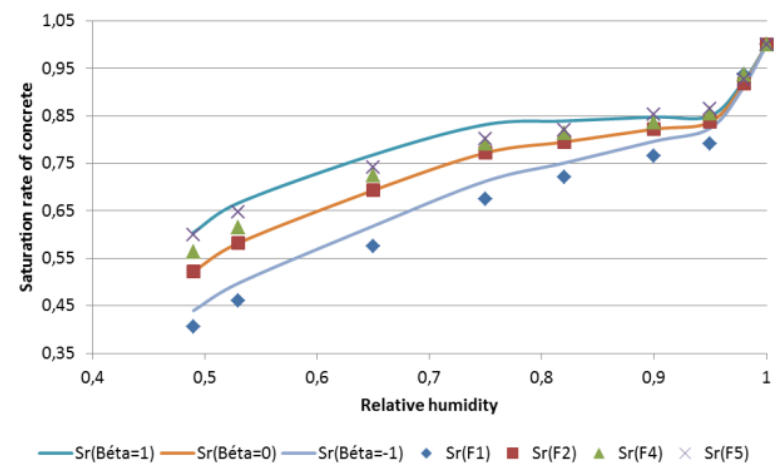

Fig. 3. Results of desorption isotherm of the concretes and simulation of different isotherm

\subsubsection{Carbonation test}

Carbonation test was performed according to the European project standard prCEN/TS 12390-12 [19]. For each concrete three samples were used to measure the carbonation depth. The $\mathrm{CO}_{2}$ concentration was $4 \%$ and the relative humidity $65 \%$. Before the carbonation test the samples were placed in a controlled environment $\left(20^{\circ} \mathrm{C}, 65 \% \mathrm{RH}\right)$ for 14 days. Figure 4 presents the carbonation depth obtained on the studied concretes at different ages.

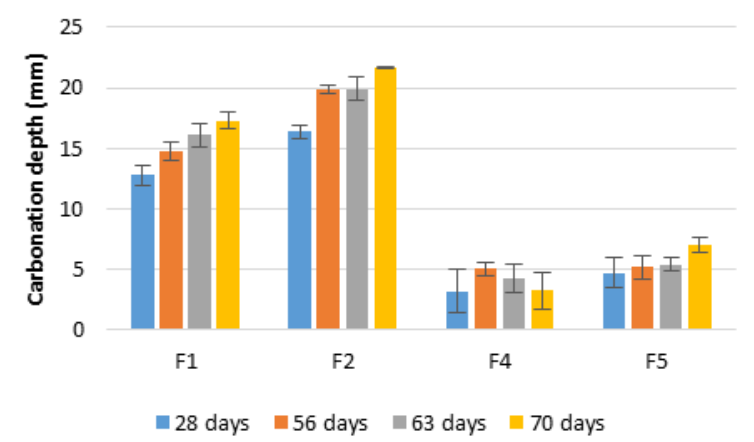

Fig. 4. Results of the carbonation test

The results of the carbonation test are used to characterize the concrete toward the carbon dioxide diffusion but also to calibrate the model on different types of concrete for the carbonation simulation.

The results show that the two compact concretes (F4 and F5) have a good resistance toward carbonation. The carbonation is less important for the concrete F5 which is compact but contains blast furnace slag than for F1 which is less compact but only contains Portland cement. The physical protection (compactness) could offset the initial consummation of the portlandite by the pozzolanic reaction when blast furnace slag is added to the mix. The chemical part of the cement matrix seems to have a lower impact on the carbon dioxide diffusion into the cement matrix than the physical properties of the concrete.

The results of this carbonation test helped us to check if the model SDReaM-crete gives acceptable values for every type of concretes (compact or not, made with Portland cement or blended cement). The following simulations were conducted considering the entire life of the concretes from the demolding to the end of the carbonation test (figure 5) and at $20^{\circ} \mathrm{C}$.

The figure 5 presents the different phases of the concretes life. Between 0 and 90 days it is the cure $(50 \%$ $\mathrm{RH}, 0.04 \% \mathrm{CO}_{2}$ ). Then there is the pre-conditionning phase between 90 and 105 days $\left(65 \% \mathrm{RH}, 0.04 \% \mathrm{CO}_{2}\right)$ and after 105 days it is the carbonation test $(65 \% \mathrm{RH}$, $4 \% \mathrm{CO}_{2}$ ).

The results of the simulations of the carbonation test (from day 105 to day 175) are given in Figure 6. The simulated carbonation depths correspond to a concrete $\mathrm{pH}$ of 9 . 


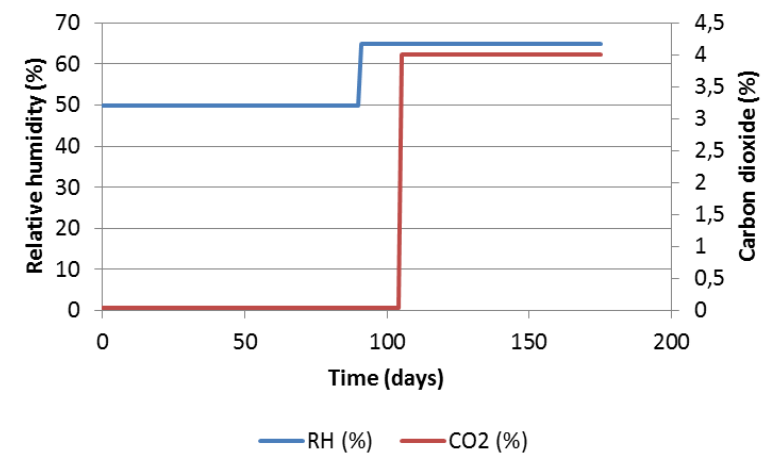

Fig. 5. Environmental conditions of the concretes

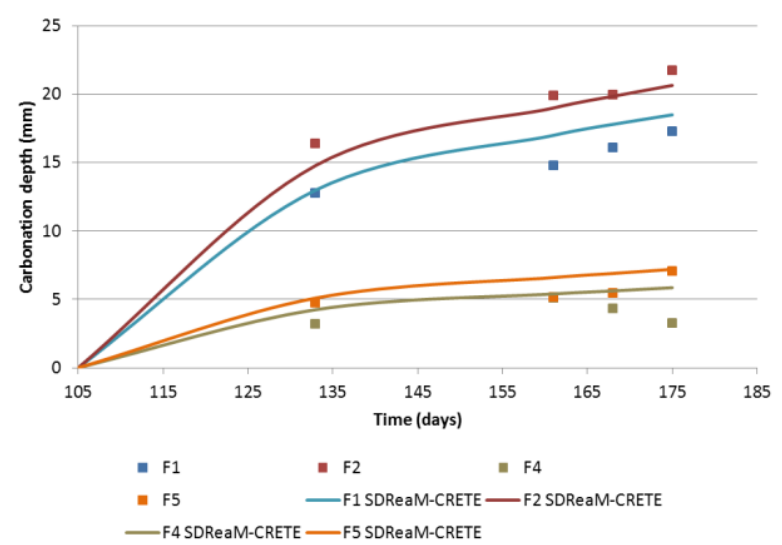

Fig. 6. Results of the simulation of the cure and the carbonation test

Figure 6 shows that the model SDReaM-crete provides results that are close to the experimental results for this accelerated test simulation. For all the type of concrete SDReaM-crete gives a good reproduction of the phenomena which have been observed during the experimental campaign.

\subsubsection{Chloride migration test}

Chloride migration test was performed according to XP P 18-462 standard [21]. This test allows the accelerated establishment of resistance to chloride penetration in concrete by determining the non-steady state migration coefficient of the chlorides. Three cylindrical test specimens were tested for each composition. The solutions were made with $\mathrm{NaOH}(0.1 \mathrm{~N})$ in upstream and downstream compartment. $\mathrm{NaCl}(0.5 \mathrm{~N})$ was added in the upstream solution. A $25 \mathrm{~V}$ voltage was applied between the sides of the concrete sample and the test was carried out at temperature $\mathrm{T}=(20 \pm 5)^{\circ} \mathrm{C}$. Figure 7 presents the apparent diffusion coefficient of the concretes at the age of 90 days.

As chloride ions are responsible for the steel corrosion in concrete, an evaluation of the diffusion properties of these ions into concrete is necessary for the simulations. We can notice that the diffusion of the chloride ions is influenced by the physical part of the concrete and the chemical part. The results put forward that F4 and F2 have the same behaviour toward the chlorides diffusion despite their formulation are different (Table 1). F2 is less compact than F4 but F2 contains blast furnace slag which is known for its capacity to bind chloride ions. On one hand we have a physical barrier (F4, compactness) and on the other hand there is a chemical barrier for the chloride ions (F2, type of binder).

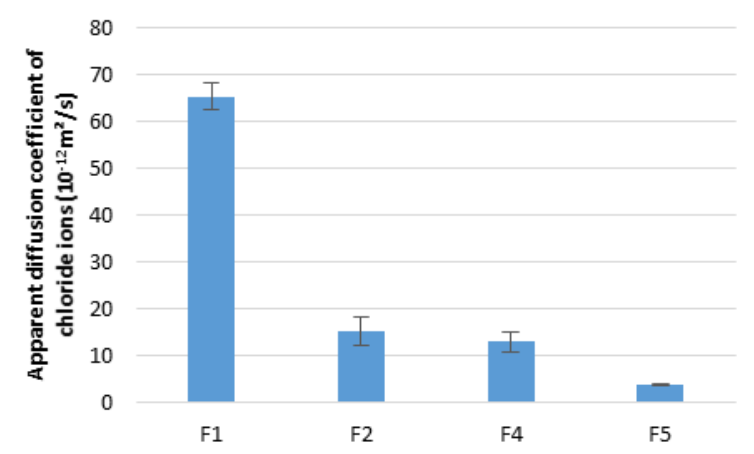

Fig. 7. Apparent diffusion coefficient of the studied concretes

\subsubsection{Results of simulations}

SDReaM-crete model has been developed to help the professionals of the concrete industry to predict the evolution of existing concrete structures or to optimize the cover thickness in function of the expected lifespan for new structures. To be as close as possible to the real structures conditions this model should allow a use which taking into account the environmental conditions.

This section presents an example of simulations for the concrete F1 presented in the Table 1 for 50 years. The annual relative humidity considered for these simulations is $(75 \pm 10) \%$ (city of Nancy) and the temperature is $20^{\circ} \mathrm{C}$. The $\mathrm{C}_{\text {min,dur }}$ thickness is taking equal to $30 \mathrm{~mm}$ according to the $\mathrm{S} 4$ class in the Eurocode 2 [22] for the durability class XC4 and for 50 years. The concrete is subject to natural carbonation $\left(0.04 \% \mathrm{CO}_{2}\right)$.

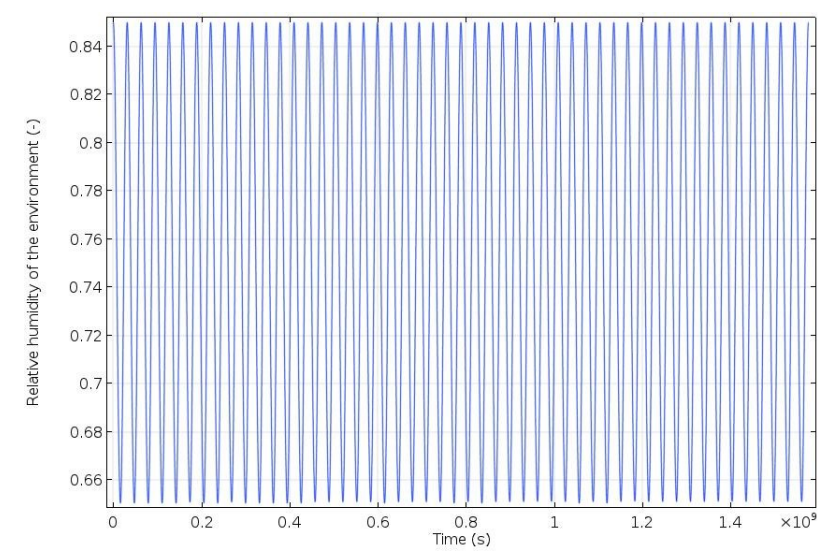

Fig. 8. Relative humidity of the simulated environment

The Figure 9 shows the result of the carbonation depth for the simulation. 


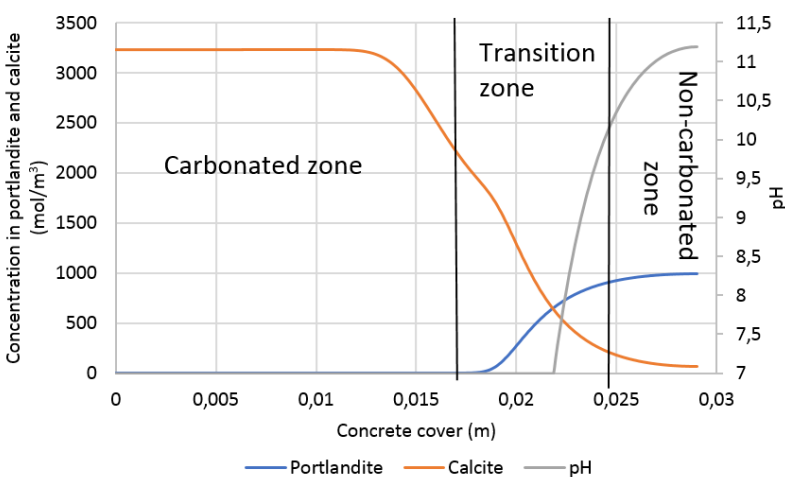

Fig. 9. Carbonation depth calculated by SDReaM-crete

On the Figure 9 we can see that portlandite, calcite and $\mathrm{pH}$ profile along the concrete cover give the same information namely the carbonation depth. In the literature we can find that the carbonation process is not instantaneous [23]. SDReaM-crete can put forward this phenomenon as the results show three zones: the noncarbonated concrete, the transition zone and the carbonated concrete.

The results of the simulation 1 show that the carbonation depth does not reach the rebar $(0.03 \mathrm{~m})$ so the depassivation (and the corrosion process) does not occur in this case.

We can know imagine that the simulated structure does not respect the Eurocode 2 [22] and has a cover thickness of $0.02 \mathrm{~m}$ for the same environment.

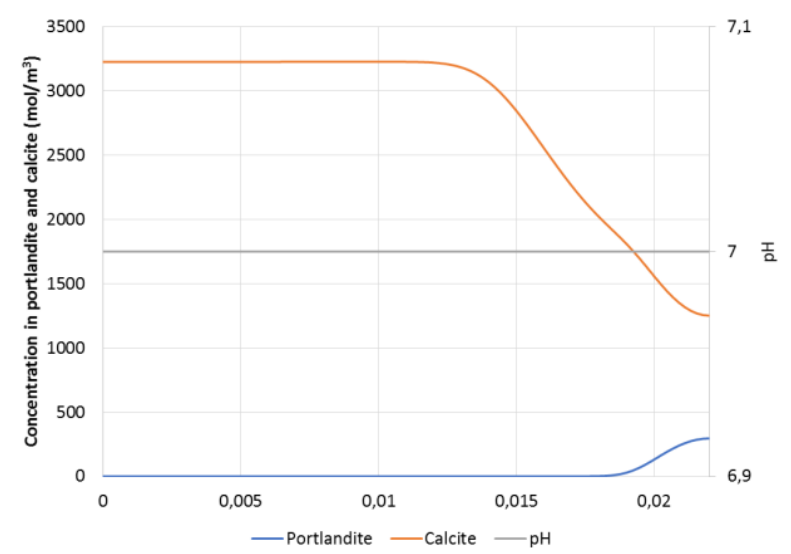

Fig. 10. Result of SDReaM-crete simulation with a cover of $0.02 \mathrm{~m}$

The Figure 10 shows that in the conditions described in the previous paragraph the carbon dioxide reaches the rebar so it induces depassivation. So, the corrosion process could start if the conditions of humidity and oxygen access are favorable. We can see in Figure 11 that the corrosion products are growing with some form of stairs following the capacity of the oxygen to reach the rebar and so following the humidity conditions (Figure 8). When the relative humidity goes up the corrosion slows down because the oxygen cannot migrate from the environment to the rebar because of the saturation rate of the concrete porosity. When the relative humidity comes down the corrosion development accelerates because the saturation of the cement matrix and its porosity decrease so the oxygen can reach the rebar.

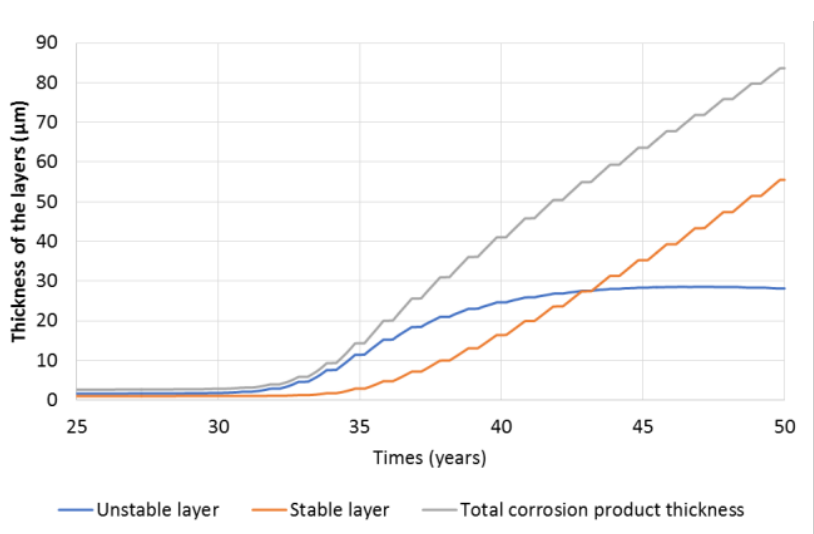

Fig. 11. Development of the corrosion in the concrete F1

In Figure 11 we can see that the unstable layer is growing firstly (see section 3 ) and then the oxides of this layer react to form the stable layer. Then the development of the unstable layer slows down because the stable layer is very dense and the oxygen cannot reach the rebar to continue the corrosion as fast as the initiation of the process.

\section{Conclusion}

Mai-Nhu [7] has developed a model coupling carbonation and chloride ingress in wetting/drying cycles as well as depassivation and the beginning of the corrosion process. In this work, the model SDReaMcrete has been improved especially the corrosion part by including the two layers of corrosion products. The simulation of the desorption isotherm has been optimized with the introduction of a homothety which allows to simulate most of concrete's isotherm. With the experimental results it has been put forward that SDReaM-crete is able to simulate in a reliable way the carbonation depth for different types of concrete.

The good results in carbonation simulations, the introduction of the two layers of corrosion products and the optimization of the isotherm makes SDReaM-crete a reference model in the lifespan prediction of concrete and a useful tool for owners to better anticipate the rehabilitation of their concrete structures and for constructors to define "concrete cover / concrete composition" couples for new construction.

An immediate follow up of this work would consist in testing SDReaM-crete in some simulations in a marine environment. Moreover a sensitivity analysis is in progress to evaluate the impact of some input data on the obtained results.

\section{References}

1. V.G. Papadakis, C.G. Vayenas, M.N. Fardis, Durability of building materials and components (1991) 
2. B. Bary, A. Sellier, Cement and Concrete Research, 34, 1859-1872 (2004)

3. N. Hyvert, Application de l'approche probabiliste à la durabilité des produits préfabriqués en béton, $\mathrm{PhD}$ thesis (2009)

4. C. Andrade, Cement and Concrete Research, 23, 724-742 (1993)

5. DuraCrete, General guidelines for durability design and redesign, $\mathrm{PhD}$ thesis (2000)

6. A. Morandeau, Carbonatation atmospherique des systèmes cimentaires à faible teneur en portlandite, $\mathrm{PhD}$ thesis (2013)

7. J. Mai-Nhu, Corrosion des armatures du béton: couplage carbonatation chlorures en présence de cycles hydriques, $\mathrm{PhD}$ thesis (2013)

8. M. Achour, A. Ouali, F. Bignonnet, E. Rozière, Workshop on multiscaled approaches towards degradation, damage and aging in geomaterials, France (2017)

9. V. L'Hostis, D. Neff, L. Bellot-Gurlet, P. Dillman, Materials and Corrosion, 60, 2 (2009)

10. W.J. Chitty, P. Dillman, V. L'Hostis, C. Lombard, Corrosion Science, 47, 1555-1581 (2005)

11. U. Angst, B. Elsener, C.K. Larsen, Y. Vennesland, Cement and Concrete Research, 39, 1122-1138 (2009)

12. X. Wang, Modélisation du transport multi-espèces dans les matériaux cimentaires saturés ou non saturés et éventuellement carbonatés, $\mathrm{PhD}$ thesis (2012)
13. J. Mai-Nhu, A. Sellier, P. Rougeau, F. Duprat, Numerical Modelling, Strategies for Sustainable Concrete Structures, France (2012)

14. H. Ranaivomanana, Transferts dans les milieux poreux réactifs non saturés : application à la cicatrisation de fissure dans les matériaux cimentaires par carbonatation, $\mathrm{PhD}$ thesis (2010)

15. B. Huet, V. L'Hostis, G. Santarini, D. Feron, H. Idrissi, Corrosion Science, 49, 1918-1932 (2007)

16. W.J. Chitty, P. Dillman, V. L'Hostis, A. Millard, Corrosion Science, 50, 3047-3055 (2008)

17. T.T.H. Nguyen, B. Bary, T. De Larrard, Cement and concrete research, 74, 95-107 (2015)

18. NF P 18-459, Essais sur béton durci - Essai de porosité et masse volumique, AFNOR (2010)

19. $\mathrm{prCEN} / \mathrm{TS}$ 12390-12, Testing hardened concrete determination of the relative carbonation resistance of concrete (2012)

20. NF EN ISO 12571, Performance hygrométrique des matériaux et produits pour le bâtiment détermination des propriétés de sorption hygroscopique, AFNOR (2013)

21. XP P 18-462, Essais sur béton durci - Essai accéléré de migration des ions chlorure en régime non stationnaire, AFNOR (2012)

22. Eurocodes - NF EN 1990 à NF EN 1999.

23. E. Drouet, Impact de la température sur la carbonatation des matériaux cimentaires - prise en compte des transferts hydriques, $\mathrm{PhD}$ thesis (2010) 